Golden Gate University School of Law GGU Law Digital Commons

\title{
Book Review of: 'Injury: The Politics of Product Design and Safety Law in the United States', by Sarah S. Lochlann Jain, Princeton University Press, 2006
}

William T. Gallagher

Golden Gate University School of Law, wgallagher@ggu.edu

Follow this and additional works at: http://digitalcommons.law.ggu.edu/pubs

Part of the Other Law Commons

\section{Recommended Citation}

Gallagher, William T., "Book Review of: 'Injury: The Politics of Product Design and Safety Law in the United States', by Sarah S. Lochlann Jain, Princeton University Press, 2006" (2008). Publications. Paper 97.

http://digitalcommons.law.ggu.edu/pubs/97 


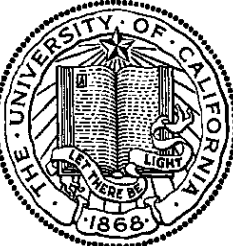

Book Review of: 'Injury: The Politics of Product Design and Safety Law in the United States', by Sarah S. Lochlann Jain, Princeton University Press, 2006

\author{
William T. Gallagher \\ Golden Gate University School of Law \\ Visiting Scholar, Center for the Study of Law and Society \\ U.C. Berkeley School of Law \\ Law and Politics Book Review, Vol. 18, p. 4, 2008
}




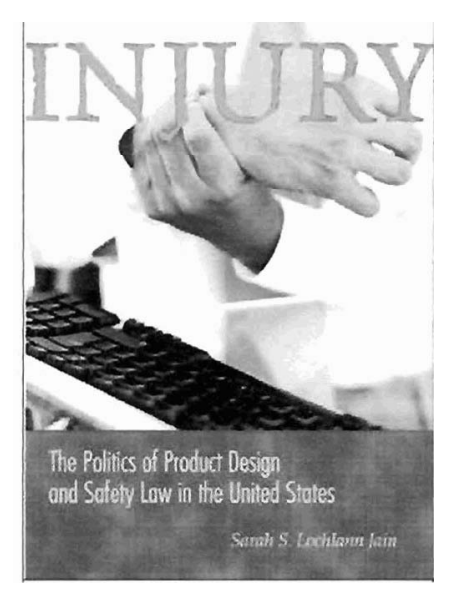

Vol. 18 No. 1 (January, 2008) pp.4-6

INJURY: THE POLITICS OF PRODUCT DESIGN AND SAFETY LAW IN THE UNITED STATES, by Sarah S. Lochlann Jain. Princeton, N.J.: Princeton University Press, 2006. 230pp.. Cloth \$57.50 / £34.95. ISBN: 9780691119076 . Paper \$22.95 / £13.50. ISBN: 9780691119083.

Reviewed by William T. Gallagher, Golden Gate University School of Law. Wgallagher [at] ggu.edu.

Anthropologist Sarah S. Lochlann Jain's book, INJURY: THE POLITICS OF PRODUCT DESIGN AND SAFETY LAW IN THE UNITED STATES, is a provocative, sophisticated, and ambitious analysis of the cultural logic of contemporary US product injury law and what Jain terms "American injury culture." Jain decodes the meanings of product injury as examined through the lens of US law, primarily legal doctrine and litigated cases. There are two mains parts to Jain's book. The first (Introduction, Chapter 1, Conclusion) consists of an extended essay analyzing the politics and cultural meanings associated with injuries that are produced by consumer and workplace products. Drawing on perspectives from cultural studies, anthropology, history, and critical theory, Jain develops several major arguments about American product injury law and "injury culture" in this section.

First, Jain provocatively argues that product injuries are not exceptional or mere "accidents." All types of products are designed in ways that impose and distribute risk and resulting injury among users. Jain analyzes how product injuries are an essential part of a market economy, part of the "human costs of capitalism" (p.20). She convincingly argues that "[a]ccidents and human wounding provide a boost to the economy that is astonishingly undertheorized" (p.154): Thus, one aim of Jain's book is to illuminate the web of social and economic interests that sustains and rationalizes the production of injuries by commercial and workplace products in the US and to examine law's role in this process.

Second, Jain develops a critique of law and its constitutive role in creating meanings of product injuries, including privileging which of those injuries will "count" in the eyes of the law. This analysis insightfully demonstrates law's role in rendering certain injuries "invisible" or, alternatively, as cognizable. Simply because a product routinely - or even inevitably - injures those who use it, does not guarantee the product design will be recognized as "defective" or unduly dangerous under product design or safety law, which is a requisite for determining that the injury is legally compensable. One important consequence, Jain argues, is that injuries caused by products are distributed unequally among populations in society and are related to such variables as race, gender, and class. Law may be only one of a number of social processes that structure "how accidents, product design, behaviors, safety, and 
progress are apprehended and valued" (p.147), but it is a powerful one. [*5]

Lastly, Jain also critiques product liability law's ability to resolve injury claims, compensate injured victims, and regulate safer product design. In this respect she is more pessimistic about law's capabilities than other critical scholars, such as Nader (2002) or Abel (1997) (both of whom Jain discusses briefly), who consider access to law as an integral - even if imperfect - tool for social justice (pp.27-28). For Jain, greater access to law is no solution, since law is primarily a discourse for "rationalizing the distribution of the inevitable and integral costs of commodity culture" (p.155).

In the second main section of her book (Chapters 2-4), Jain develops these arguments through a creative cultural and historical analysis of three legal disputes involving products that have injured different groups of victims. The first dispute (Chapter 2) involves litigation in California in the mid-1970s brought by public interest lawyers on behalf of Mexican and Mexican-American farm workers who were injured while using the notorious short-handled hoe to cultivate agricultural crops. Prolonged use of the hoe under conditions mandated by the needs of agribusiness - which included forcing workers to use the hoe in an awkward (and demeaning) bent-from-the-waist "stoop" position while quickly walking down rows of crops - caused often debilitating back and other injuries. This litigation was ultimately successful in establishing that the short-handled hoe constituted a "dangerous hand tool" under state health and safety regulations, which led to its ban. Although the short-handled hoe had been used for decades, it was through this litigation, Jain explains, that the injuries its use caused was recognized as the result of the hoe's defects rather than as the inevitable byproduct of farm labor in general or of the presumed "defectiveness" of Mexican farm worker bodies, which both growers and some in the medical community asserted were predisposed to these types of injury (pp.77-78).

The second dispute (Chapter 3) focuses on product liability lawsuits that were filed in the 1990s against computer keyboard manufacturers for repetitive strain injuries (RPIs) to hands and wrists (such as carpal tunnel syndrome) suffered primarily by female office workers. Plaintiffs in these lawsuits were spectacularly unsuccessful, since no single litigated case resulted in a finding of liability that survived appeal. As Jain shows, the constraints and assumptions of product injury law made it difficult to establish that RPIs were caused by the allegedly defective keyboard design rather than from any particular worker's manner of keyboard use or from other causes, such as female hysteria or even hormones (pp.108-109).

The third dispute (Chapter 4) involves an unsuccessful class-action lawsuit brought against major tobacco companies in the late 1990s on behalf of a class of African-American smokers. The lawsuit creatively alleged that decades of aggressive marketing of dangerous and highly-addictive mentholated cigarettes to African-Americans constituted a civil rights violation under federal law (pp.124-127). By suing under civil rights statutes rather than product liability laws, the plaintiffs were able to seek, albeit unsuccessfully, a unique remedy for the product-related injuries they alleged [*6] were caused by menthol cigarettes: prevention of further injuries by banning race-based targeted tobacco advertising (p.141). Jain's analysis demonstrates and decodes how this litigation highlighted product liability claims in a race-recognized context.

Jain describes these three dispute narratives as "genealog[ies] of how particular injuries and objects have come to be understood at particular moments" (p.8). Tellingly, she insists that these narratives are not "case studies" intended to prove (rather than to provide examples of) her arguments (p.8) - and they are not, in the traditional social-scientific use of that term. Only one narrative, (Chapter 2 ) is based

significantly on primary source material such as archival data, legal briefs, hearing transcripts, and select participant interviews. The other two (Chapters 3 and 4) are based mostly on an interpretive reading of 
published legal decisions, media images such as advertisements and cartoons, and analysis of secondary literature. Thus, readers of INJURY will have to be amenable to Jain's eclectic cultural studies methodology in order to appreciate the insights these narratives provide.

Overall, INJURY is a significant contribution to the growing body of scholarship on the cultural foundations and meanings of tort law, including work that examines the intersection of tort law, race, gender, and power. Jain's specific focus on the recent history of how certain products have come to be understood as dangerously "defective" or not is particularly illuminating and insightful. Yet, I have several criticisms of the book. First, Jain's critique of the limitations of law and legal discourse and the ineffectiveness of law for redressing injury or regulating product design is not entirely new. Certainly this is by now a mainstream criticism in much law and society or critical legal scholarship. Perhaps more importantly, Jain's contention that American law and injury culture are decidedly unique remains underdeveloped. Jain may be correct, but just as with the many assertions made by others about the alleged uniqueness of various aspects of American legal culture - such as Americans' supposed "litigiousness" - Jain's claims about the exceptionalism of American injury culture require more careful and nuanced comparative analysis to be fully convincing. Finally, I found the writing style of INJURY to be uneven. Frankly, I find some of Jain's other work (e.g., Jain 2004) to be clearer and easier to read. Yet, these are relatively minor criticisms of this fascinating and important book.

\section{REFERENCES:}

Abel, Richard. 1997. "The Real Tort Crisis - Too Few Claims." 48 OHIO STATE LAW JOURNAL 443-467.

Jain, Sarah S. Lochlann. 2004. "'Dangerous Instrumentality': The Bystander as Subject in Automobility." 19 CULTURAL ANTHROPOLOGY 61-94.

Nader, Laura. 2002. THE LIFE OF THE LAW: ANTHROPOLOGICAL PROJECTS. Berkeley: University of California Press.

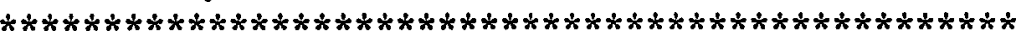

(C) Copyright 2008 by the author, William T. Gallagher. 